\title{
Correction to: Rat limbal niche cells can induce transdifferentiation of oral mucosal epithelial cells into corneal epithelial-like cells in vitro
}

\author{
X. Y. Zhao' ${ }^{1}$ H. T. Xie ${ }^{1}$, C. Y. Duan' ${ }^{1}$, J. Li ${ }^{2}$ and M. C. Zhang ${ }^{1 *}$
}

\section{Correction}

The original article [1] contains an error in Fig. 5e whereby the immunofluorescence of $\Delta \mathrm{Np} 63 \alpha$ in the ME group is incorrectly presented; thus, the corrected figure is shown ahead.

\begin{abstract}
Author details
'Department of Ophthalmology, Union Hospital, Tongji Medical College, Huazhong University of Science and Technology, Wuhan 430022, China. ${ }^{2}$ Department of Ophthalmology, Tongji Hospital, Tongji Medical College, Huazhong University of Science and Technology, Wuhan 430022, China.
\end{abstract}

Received: 8 October 2018 Revised: 8 October 2018

Accepted: 8 October 2018 Published online: 25 October 2018

\section{Reference}

1. Zhao X-Y, et al. Rat limbal niche cells can induce transdifferentiation of oral mucosal epithelial cells into corneal epithelial-like cells in vitro. Stem Cell Res Ther. 2018;9:256 https://doi.org/10.1186/s13287-018-0996-9.

\footnotetext{
* Correspondence: mingchangzhang@hotmail.com

1 Department of Ophthalmology, Union Hospital, Tongji Medical College,

Huazhong University of Science and Technology, Wuhan 430022, China
} 


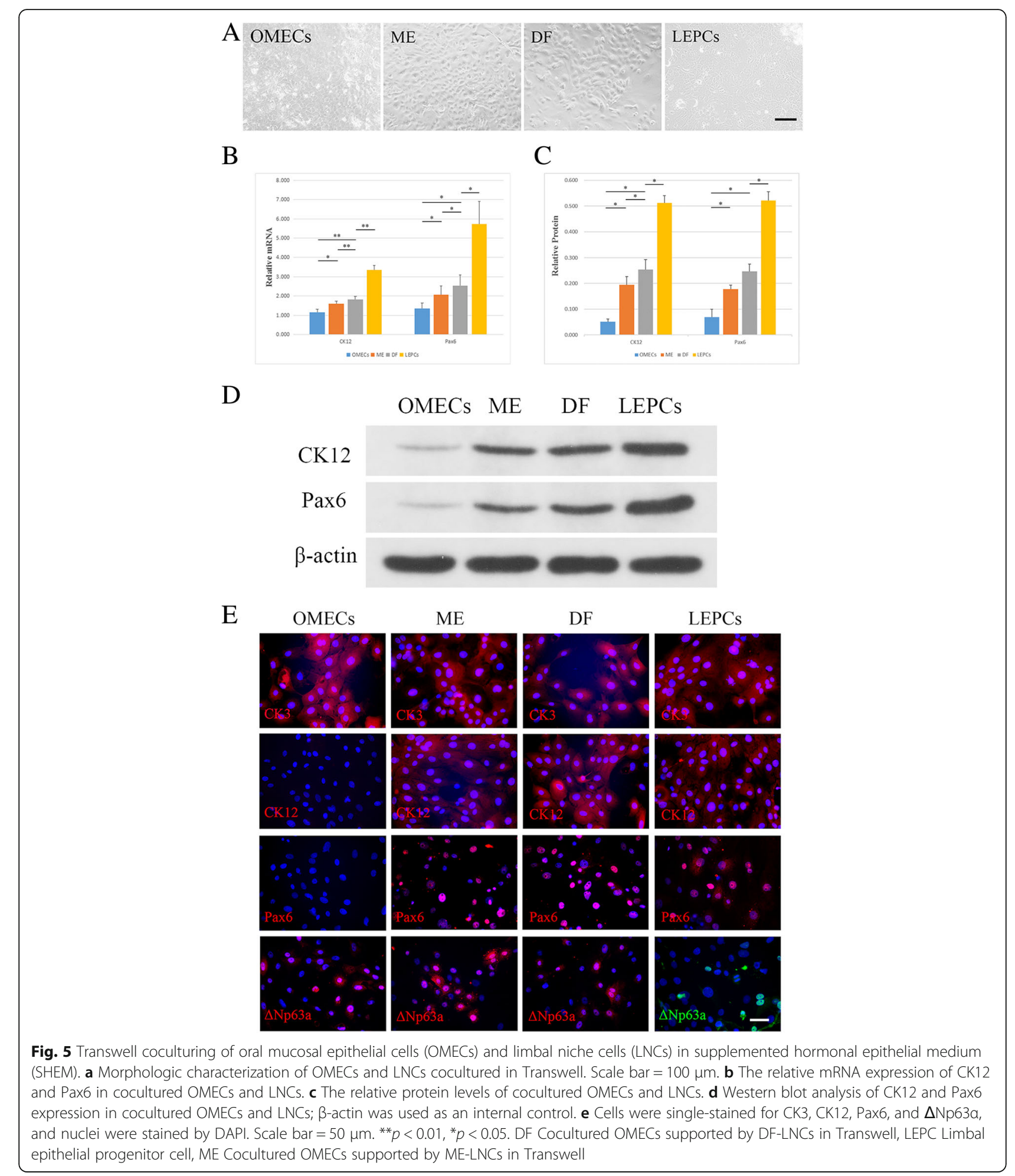

